\title{
New delivery systems and propellants
}

\author{
Myrna Dolovich P Eng \\ Department of Medicine, Faculty of Health Sciences, \\ McMaster University, Hamilton, Ontario
}

\section{Dolovich. New delivery systems and propellants. Can Respir J 1999;6(3):290-295.}

The removal of chlorofluorocarbon (CFC) propellants from industrial and household products has been agreed to by over 165 countires of which more than 135 are developing countries. The timetable for this process is outlined in the Montreal Protocol on Substances that Deplete the Ozone Layer document and in several subsequent amendments. Pressured metered dose inhalers (pMDIs) for medical use have been granted temporary exemptions until replacement formulations, providing the same medication via the same route, and with the same efficacy and safety profiles, are approved for human use. Hydrofluoroalkanes (HFAs) are the alternative propellants for CFCs-12 and -114. Their potential for damage to the ozone layer is nonexistent, and while they are greenhouse gases, their global warming potential is a fraction (one-tenth) of that of CFCs. Replacement formulations for almost all inhalant respiratory medications have been or are being produced and tested; in Canada, it is anticipated that the transition to these HFA or CFC-free pMDIs will be complete by the year 2005. Initially, an HFA pMDI was to be equivalent to the CFC pMDI being replaced, in terms of aerosol properties and effective clinical dose. However, this will not necessarily be the situation, particularly for some corticosteroid products. Currently, only one CFC-free formulation is available in Canada - Airomir, a HFA salbutamol pMDI. This paper discusses the in vitro aerosol characteristics, in vivo deposition and clinical data for several HFA pMDIs for which there are data available in the literature. Alternative delivery systems to the pMDI, namely, dry powder inhalers and nebulizers, are briefly reviewed.

Key Words: Aerosol delivery devices; Beclomethasone; HFA propellants; Metered-dose inhalers; Montreal Protocol; Salbutamol

\section{Nouveaux dispositifs de délivrance des médica- ments et gaz de substitution}

RÉSUMÉ : Le retrait des produits domestiques et industriels des propulseurs contenant des chlorofluorocarbones (CFC) a été approuvé par plus de 165 pays dont plus de 135 sont des pays en voie de développement. L'échéancier de ce processus est présenté dans le document intitulé Protocole de Montréal relatif à des substances qui appauvrissent la couche d'ozone et dans plusieurs de ses amendements subséquents. Les aérosols-doseurs à usage médical ont été temporairement exemptés jusqu'à ce que des formules de substitution, fournissant le même médicament par la même voie d'administration, et avec les mêmes profils d'efficacité et d'innocuité, soient approuvées pour utilisation chez l'humain. Les hydrofluoroalkanes (HFA) ont été choisis comme gaz de substitution des CFC-12 et CFC-114. Leur potentiel d'appauvrissement de la couche d'ozone est inexistant, et alors qu'ils sont des gaz à effet de serre, leur potentiel global de réchauffement représente une fraction (un dixième) de celui des CFC. Des formules de substitution pour presque tous les médicaments respiratoires administrés par inhalation ont été et sont testées. Au Canada, on espère que la transition vers ces aérosols-doseurs générés aux HFA ou ne contenant pas de CFC sera terminée vers 2005. Initialement, un aérosol-doseur généré par HFA devait être équivalent à l'aérosol-doseur généré par CFC que l'on remplaçait, relativement aux propriétés de l'aérosol et à la dose clinique efficace. Cependant, ce ne sera pas nécessairement le cas, en particulier pour certains produits contenant des corticostéroïdes. Actuellement, une seule formulation sans CFC est disponible au Canada - Airomir, un aérosol-doseur contenant du salbutamol et généré par HFA. Le présent article discute des caractéristiques de l'aérosol in vitro et du dépôt in vivo, et des données cliniques obtenues sur plusieurs aérosols-doseurs générés par HFA et sur lesquels des données sont disponibles dans la littérature. L'alternative aux aérosols-doseurs, à savoir, les inhalateurs à poudre sèche et les nébuliseurs, sont brièvement passés en revue. 
$\mathrm{I}$ 1987, 140 countries signed the final draft of the Montreal Protocol on Substances that Deplete the Ozone Layer, the document that outlined the procedures and timetable to be followed for phasing out the use of chlorofluorocarbon (CFC) propellants in industry. Exemptions are made yearly for essential uses of CFCs, and the medical use of CFCs in pressurized metered dose inhalers (pMDIs) for the treatment of asthma and chronic obstructive pulmonary diseases falls into this category. Applications to use CFCs must be negotiated yearly for use in two years and should be viewed as temporary extensions of the projected time to complete elimination because allowances may not be granted after the year 2005. In Canada, the criteria that must be met before phasing-out of CFC propellants in pMDIs have been outlined in the Canadian Initial Transition Strategy for the Phase-Out of Chlorofluorocarbon (CFC) use in Metered Dose Inhalers (MDIs) draft document from Health Canada and Environment Canada, developed after consultation with representatives from medical and allied health professional organizations, patient information groups, environmental groups, the pharmaceutical industry and various government departments. This initial document has been circulated (1) but is not yet finalized.

\section{CFC PHASE-OUT OBJECTIVES}

In Canada, the majority opinion of those consulted favoured adopting a transition policy based on a drug-by-drug removal protocol rather than the phase-out of a specific drug category. Thus, as a particular CFC-free pMDI is approved for use, the CFC pMDI is removed from the provincial formularies, but only after a reasonable period of time during which both products are available for therapy. Before the removal of a specific drug and the transition to the replacement formulation can occur, sufficient quantities of the alternative drug must be available from the pharmaceutical companies, as well as sufficient types of alternatives to meet the needs of different patient groups. At least 12 and possibly 18 months of postmarketing surveillance data must also be obtained to confirm the (long term) safety of replacement formulations.

One of the main goals of the Canadian Initial Transition Strategy is to reduce the need for CFC pMDI use by $60 \%$ by the year 2001 and to achieve complete phase-out by the year 2005. Most respiratory medications are also available in Canada as products dispensed via the other two major categories of aerosol delivery systems, ie, dry powder inhalers (DPIs) and nebulizers (Figure 1). Only two drugs are available solely as DPIs, Bricanyl Turbuhaler (Astra Pharma, Mississauga, Ontario) and Foradil (Novartis, Dorval, Quebec). Data available for 1996 usage indicate that CFC pMDIs accounted for $79 \%$ of the perscriptions for aerosol drug delivery systems, DPIs $13 \%$ and nebulizers $8 \%$ (2). In Canada, there are 18 approved active ingredients used to treat respiratory diseases by inhalation. Approximately 11 million pMDIs inhalers were sold across the country in 1996, and, of these, $57.5 \%$ were beta-agonists, predominantly salbutamol sulphate $(55.4 \%$ or $5,900,334$ units). Inhaled corticosteroids accounted for a further $25.8 \%$ of the total, with beclometha-

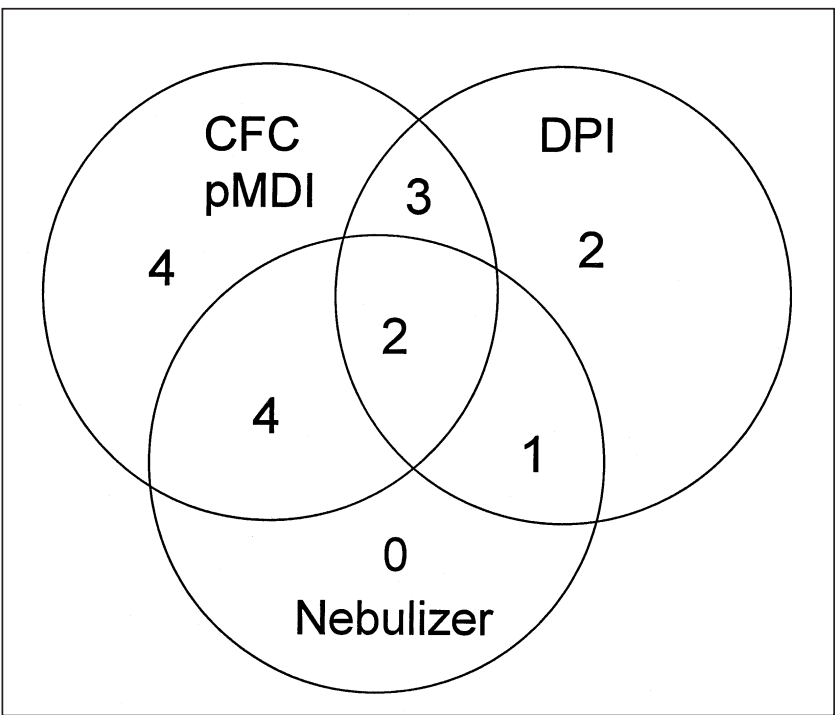

Figure 1) Packaging of inhalant therapies in Canada for the three main categories of aerosol delivery systems. CFC Chlorofluorocarbon; DPI Dry powder inhaler; pMDI Pressured metered dose inhaler

sone dipropionate (BDP) comprising $21.9 \%$ or $2,329,793$ units. A possible way of achieving the 2001 target could be to remove CFC salbutamol from the market, because there are alternative delivery systems in place (Figure 1).

\section{CFC AND HFAs: ENVIRONMENTAL CONCERNS}

CFCs are nontoxic, stable chemicals containing carbon, chlorine and fluorine (Table 1). Originally manufactured for industrial uses, mainly refrigeration and foam insulation products, their advantage as the energy source for producing pharmaceutical aerosols was recognized in the mid-1950s. The medical use of CFCs has accounted for less than $1 \%$ of the total production of CFCs; however, with the elimination of CFCs for industrial uses and in household products, this percentage has increased, with parallel increases in the cost of production for this limited medical market.

The observation that CFCs cause atmospheric ozone depletion was made by Molina and Rowland in 1974 (3). The resulting long term environmental and health effects of CFCs are a major global concern and caused a limited ban on the nonmedical use of CFCs to be enforced in several countries in the late 1970s. The Vienna Convention was drawn up in 1985, culminating in the Montreal Protocol in 1987. Three amendments to the protocol have been made that have accelerated the original time frame for the complete removal of CFCs (4).

The replacement propellants, hydrofluroalkanes (HFAs) -134a and -227 have physicochemical properties similar to the three CFCs that are used in medical inhalers (Table 1), but with no ozone depleting potential and a much smaller likelihood of contributing to global warming compared with CFCs. HFAs are much less damaging to the environment, are nontoxic and can be substituted for CFC-12 (HFA-134a) and CFC-114 (HFA-227) in medical pMDIs. There is no substitute HFA for CFC-11. The differences in the physical proper- 
TABLE 1

Physicochemical and atmospheric properties of propellants used in pressured metered dose inhalers

\begin{tabular}{|c|c|c|c|c|c|c|c|c|}
\hline Propellant & Formula & Common name & $\begin{array}{c}\text { Density } \\
\text { g/cc } \\
\text { at } 20^{\circ} \mathrm{C}\end{array}$ & $\begin{array}{c}\text { Vapor } \\
\text { pressure } \\
\text { psi @ } 20^{\circ} \mathrm{C}\end{array}$ & $\begin{array}{l}\text { Boiling } \\
\text { point }\end{array}$ & $\begin{array}{c}\text { Atmospheric } \\
\text { life } \\
\text { years }\end{array}$ & $\begin{array}{c}\text { Global } \\
\text { warming } \\
\text { potential }\end{array}$ & $\begin{array}{c}\text { Ozone } \\
\text { depleting } \\
\text { potential* }^{*}\end{array}$ \\
\hline HFA-134a & $\mathrm{C}_{2} \mathrm{H}_{2} \mathrm{~F}_{4}$ & Tetrafluoroethane & 1.21 & 70 & $-27^{\circ} \mathrm{C}$ & 16 & 0.26 & 0 \\
\hline HFA-227 & $\mathrm{C}_{3} \mathrm{HF}_{7}$ & Heptafluoropropane & 1.41 & 40 & $-17^{\circ} \mathrm{C}$ & 33 & 0.3 & 0 \\
\hline CFC-11 & $\mathrm{CCl}_{3} \mathrm{~F}$ & Trichlorofluoromethane & 1.49 & -1.8 & $+24^{\circ} \mathrm{C}$ & 60 & 1 & 1.0 \\
\hline CFC-12 & $\mathrm{CCl}_{2} \mathrm{~F}_{2}$ & Dichlorodifluoromethane & 1.33 & 67.6 & $-30^{\circ} \mathrm{C}$ & 125 & 3 & 0.9 \\
\hline CFC-114 & $\mathrm{C}_{2} \mathrm{CL}_{2} \mathrm{~F}_{4}$ & Dichlorotetrafluorethane & 1.47 & 11.9 & $+4^{\circ} \mathrm{C}$ & 200 & 3.9 & 0.7 \\
\hline
\end{tabular}

*Ozone depleting potential is set relative to chlorofluorocarbon (CFC)-11, which is assigned a value of 1.0

TABLE 2

Salbutamol chlorofluorocarbon (CFC) and hydrofluoroalkane (HFA) pressured metered dose inhalers formulations

\begin{tabular}{lcc}
\hline Ingredients & $\begin{array}{c}\text { Ventolin } \\
\text { Glaxo-Wellcome, } \\
\text { Ware, UK }\end{array}$ & $\begin{array}{c}\text { Airomir } \\
\text { 3M Pharma, } \\
\text { St Paul, Minnesota }\end{array}$ \\
\hline Propellants & CFC-12 & HFA-134a \\
Surfactant & CFC-11 & Oleic acid \\
Cosolvent & Oleic acid & Ethanol \\
Drug & Salbutamol & $\begin{array}{c}\text { Salbutamol sulphate } \\
\text { (equivalent to } 100 \mu \mathrm{g} \\
\text { salbutamol) }\end{array}$ \\
\hline
\end{tabular}

ties, coupled with the lack of compatible surfactants for these replacement propellant fomulations necessitating changes to the hardware (canister valves and seals), have resulted in different aerosol characteristics for some inhalers.

\section{HFA pMDIs}

Very few widely used CFC pMDIs are not being reformulated as HFA pMDIs. The formulations in development are to be the same as the current CFC product in terms of nominal dose per actuation and particle size characteristics. This has proven mostly true for beta-agonists under development, but is not universal for HFA steroids. Because corticosteroids are readily soluble in ethanol and, hence, are then dissolved in the replacement propellant, HFA-134a, some of these formulations have become solutions rather than suspensions. In some instances, the steroid sprays are finer than the CFCs, but because there are limited published data, this may not be true for all steroid HFA inhalers. In Canada, there is currently only one approved replacement propellant pMDI, namely, Airomir (3M Pharmaceutials, London, Ontario), a HFA-134a salbutamol sulphate inhaler.

HFA salbutamol: Table 2 lists the ingredients for CFC Ventolin pMDI (Glaxo Wellcome, Mississauga, Ontario) compared with Airomir. The composition of the HFA formulation is different, requiring salbutamol sulphate as the active ingredient rather than salbutamol. However, the quantities have been adjusted to deliver $100 \mu \mathrm{g}$ of salbutamol per actuation. In addition, Airomir contains a small quantity of ethanol, but it is not sufficient to alter the particle size of this replacement formulation. There are differences, however, in the physical properties of the spray compared with CFC Ven- tolin. The spray temperature is above freezing $\left(+14^{\circ} \mathrm{C}\right.$ versus $\left.-2^{\circ} \mathrm{C}\right)(5)$, and the jetting force of the spray is much reduced (2.4 milliNewtons versus 6.2 milliNewtons) (6). The warmer spray should alleviate the cold Freon effect that many patients experience on taking their CFC MDIs, particularly children, and the reduction in the spray velocity should reduce the oropharyngeal dose. Compared with CFC salbutamol, the HFA pMDI spray looks different mainly because of the reduced jetting velocity, sounds different for the same reason, and tastes different, largely due to the ethanol, which has recently been reported to cause a transient increase in breath alcohol levels (7). Clinically, the effects and incidence of side effects are similar as has been demonstrated in a number of clinical trials (8-11).

Reformulation plus the hardware improvements have also resulted in better canister performance. Compared with CFC pMDIs, there is no reduction in the dose per actuation when the inhaler is not used for several hours, an effect extending up to two weeks. The emitted dose per actuation is consistent through the life of the canister, ie, there is no tail-off of drug available when the canister is almost empty, and there is no reduction in the emitted dose at ambient temperatures as low as $-20^{\circ} \mathrm{C}$. Thus, in the winter, asthmatics should not receive less drug per puff if the HFA canister is left in the car or carried in a purse or briefcase, for example.

The particle size distribution of Airomir versus Ventolin has been shown to be the same (Figure 2) $(12,13)$. The mass median aerodynamic diameter of Airomir is $2.69 \mu \mathrm{m}$ versus $2.62 \mu \mathrm{m}$ for Ventolin, but the fine particle fraction of the emitted dose as inhaled into the lung contained in particles less than $5.8 \mu \mathrm{m}$ in diameter was greater for Airomir $(65.5 \%$ versus $41.4 \%, \mathrm{P}<0.05)(13,14)$. The emitted doses are different, being less for Airomir than Ventolin $(85.3 \pm 5.4 \mu \mathrm{g}$ versus $96.9 \pm 6.9 \mu \mathrm{g}$, p.05) (13), but, because the fine particle fraction is greater for Airomir, this translates into a fine particle dose for Airomir of $54.2 \mu \mathrm{g}$ compared with that of $40.3 \mu \mathrm{g}$ for Ventolin. When Airomir was used with several spacers of different volumes, the fine particle dose was enhanced and comparable between all spacers: approximately $70 \mu \mathrm{g}$ was measured at the mouthpiece of the Aerochamber (Trudell Medical International, London, Ontario) or Babyhaler (Glaxo Wellcome, Ware, United Kingdom) or metal Nebuchamber (Astra Pharma, Lund, Sweden) (13,14). A series of pharmcokinetic studies in normal subjects from Lipworth and co-workers (15) have demonstrated increased plasma 

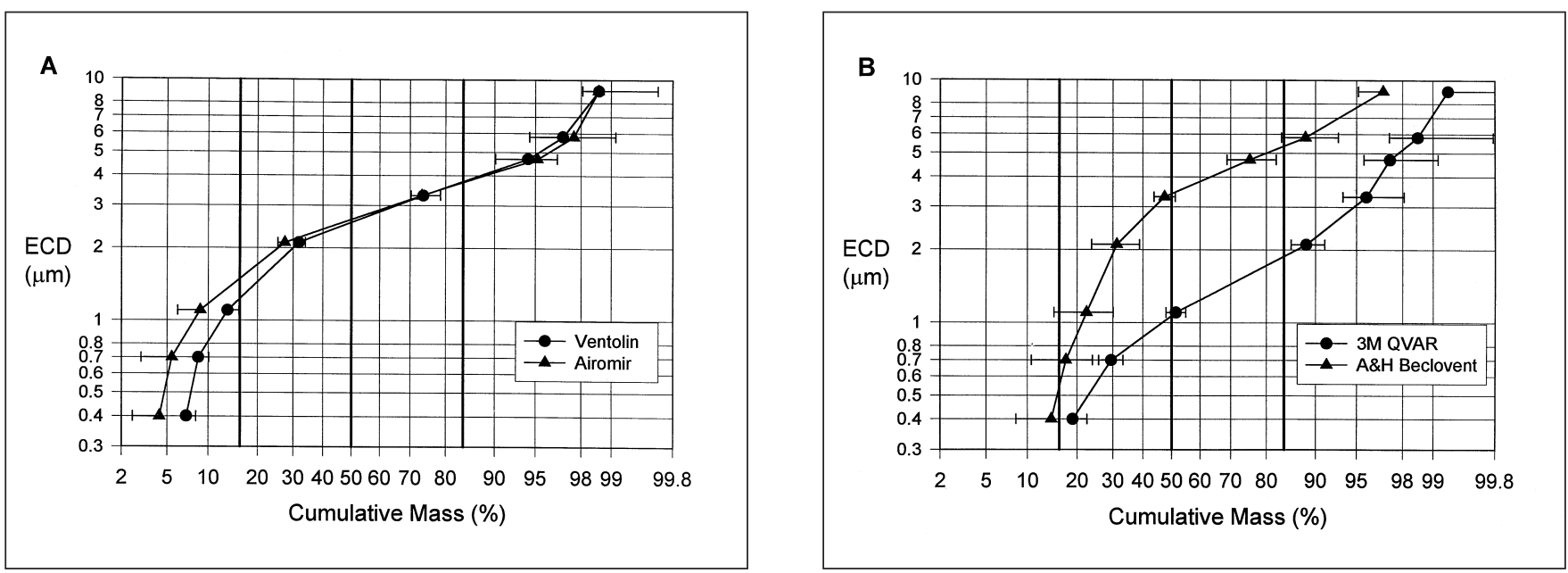

Figure 2) Hydrofluoroalkane (HFA) versus chlorofluorocarbon (CFC) particle size distributions for (A) Airomir (HFA) 3M Pharmaceutials, London, Ontario and Ventolin pMDI (CFC) (Glaxo Wellcome, Mississauga, Ontario) and (B) QVAR (HFA) (3M Pharmaceuticals, St Paul, Minnesota) and Beclovent (CFC) (Glaxo Wellcome, Mississauga, Ontario). Measurements were obtained using the Anderson Cascade Impactor operated at $28.3 \mathrm{Lpm}$. Cumulative mass (\%) refers to aerosolized drug that is deposited in the Anderson Cascade Impactor only. ECD Effective cut-off diameter

levels with HFA salbutamol inhaled through both plastic and metal spacers compared with either the HFA pMDI alone or salbutamol delivered through the Turbuhaler (16), supporting greater total deposition in the lung of HFA salbutamol.

HFA steroids: Transition to HFA pMDI aerosols has, by necessity, produced different formulations for some existing drugs, resulting in aerosols with particle size characteristics which are not the same as the CFC products that they are replacing. Beclomethasone diproprionate (BDP) is one such example. QVAR (3M Pharmaceuticals, St Paul, Minnesota) is the CFC-free formulation that is expected to be approved shortly in Canada. Its aerosol characteristics are quite different to the existing CFC BDP (Beclovent, Glaxo Wellcome, Ware, United Kingdom) owing to the changes in the formulation. Without a compatible surfactant, BDP, of necessity, is dissolved in ethanol to make it soluble in the propellant (HFA-134a). Thus, the formulation produces a solution rather than the suspension aerosol as with the CFC pMDI (12). As with Airomir, the temperature of the QVAR spray is above freezing and the spray velocity reduced (6). Stability of the emitted dose with short term storage and tail-off effects are similar to Airomir.

The results for emitted dose and particle size measurements for QVAR and Beclovent are given in Table 3. Emitted doses are the same for both formulations, but QVAR is a much finer aerosol, with all of the emitted dose well within the respirable range. Radiolabelled deposition studies comparing QVAR with CFC Beclovent have shown a 10-fold increase in lung deposition of the HFA BDP (Table 4) $(12,17)$. In addition, the oropharyngeal deposition from a QVAR puff is reduced by approximately one-third and further decreased with the use of the Aerochamber (Table 5). Because of the particle size characteristics of the aerosol, approximately $10 \%$ of the dose will be exhaled (12), even with a breath-hold.

Values are given in Table 4 for one other reformulated steroid for which there are published data, namely HFA flu-
TABLE 3

Emitted dose and aerosol size characteristics* of $3 \mathrm{M}$ Pharmaceuticals (St Paul, Minnesota) hydrofluoroalkane (HFA)-134a beclomethasone dipropionate (BDP) versus A\&H chlorofluorocarbon (CFC) Beclovent (Glaxo Wellcome, Ware, United Kingdom)

\begin{tabular}{|c|c|c|}
\hline & $\begin{array}{c}\text { 3M HFA-134a } \\
\text { BDP }\end{array}$ & $\begin{array}{l}\text { A\&H CFC } \\
\text { Beclovent }\end{array}$ \\
\hline Emitted dose $(\mu \mathrm{g})$ & $40.6 \pm 3.2$ & $45.0 \pm 3.6$ \\
\hline $\begin{array}{l}\text { Mass median aerodynamic } \\
\text { diameter }(\mu \mathrm{m})\end{array}$ & $1.07 \pm 0.07$ & $3.36 \pm 0.24$ \\
\hline Geometric standard deviation & $1.87 \pm 0.04$ & $1.63 \pm 0.19$ \\
\hline Percentage less than $4.7 \mu \mathrm{m}$ & $96.8 \pm 2.1$ & $76.9 \pm 4.8$ \\
\hline
\end{tabular}

*Measured with the Anderson Cascade Impactor (Graeby Anderson, Smyrna, Georgia) at $28.3 \mathrm{Lpm}$

nisolide (Aerobid, Forest Labs, New York, New York); this also shows a trend towards increased deposition compared with the CFC pMDI in the control subjects studied and patients with asthma (18). Both products are solutions, which may explain this similarity. Lung deposition for the HFA flunisolide was enhanced and oropharyngeal deposition reduced with the addition of a valved spacer (Table 5), again confirming that these devices are of benefit when used with the replacement propellant pMDIs. Pharmacokinetic studies only have been performed with CFC versus HFA-134a fluticasone (Flovent, Glaxo Wellcome, United Kingdom) and indicate similar systemic bioavailability (19).

A number of dose comparison studies between Beclovent and QVAR have indicated that a 2.5 -fold reduction in the prescribed dose of QVAR will give similar efficacy to Beclovent, with the same safety profile (20).

\section{ALTERNATIVE DELIVERY SYSTEMS}

The need to eliminate CFC-containing pMDIs has provided the impetus to develop new, non-CFC dependent aero- 
TABLE 4

Lung deposition of hydrofluoroalkane (HFA) versus chlorofuorocarbon (CFC) steroid pressured metered dose inhaler formulations

\begin{tabular}{|c|c|c|c|c|c|}
\hline Drug & Deposition method & Reference & Group & CFC* & HFA* $^{*}$ \\
\hline $\begin{array}{l}\text { Beclomethasone dipropionate } \\
\text { (HFA, 3M, St Paul, Minnesota); } \\
\text { (CFC Glaxo Wellcome, Ware, } \\
\text { United Kingdom) }\end{array}$ & $\begin{array}{l}\text { 2D gamma } \\
\text { scintigraphy }\end{array}$ & Leach et al 1998 (17) & Normal $n=8$ & $5 \%$ & $56 \%$ \\
\hline $\begin{array}{l}\text { Flunisolide (Forest Labs, New York, } \\
\text { New York) }\end{array}$ & $\begin{array}{l}\text { 2D gamma } \\
\text { scintigraphy }\end{array}$ & Richards et al 1998 (18) & $\begin{array}{c}n=4,10 \\
(\mathrm{CFC}, \mathrm{HFA})\end{array}$ & $17 \%$ & $22.6 \%$ \\
\hline $\begin{array}{l}\text { Fluticasone propionate } \\
\text { (Glaxo Wellcome, United Kingdom) }\end{array}$ & Pharmakokinetic & Johnson et al 1998 (19) & Normal $n=8$ & $26.4 \%$ & $26.6 \%$ \\
\hline
\end{tabular}

*Mean lung deposition

TABLE 5

Deposition of hydrofluoroalkane HFA-134a steroid pressured metered dose inhalers and spacers

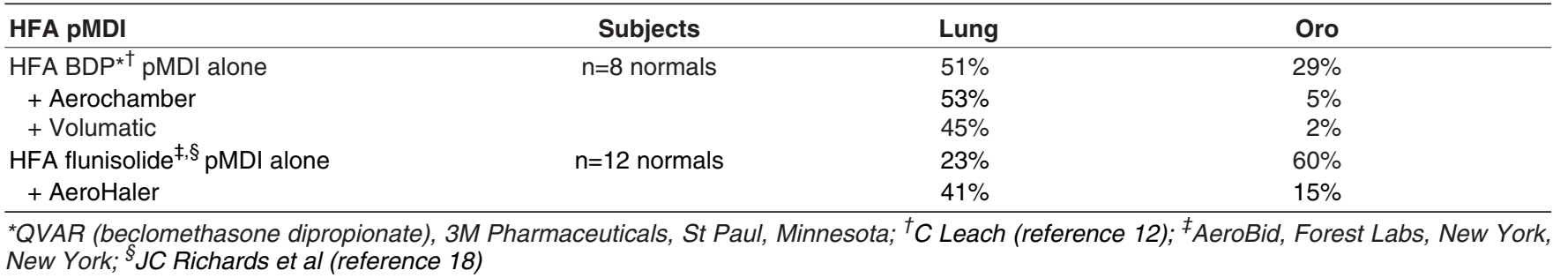

TABLE 6

Lung deposition from several marketed dry powder inhalers (DPIs) measured at the optimal inspiratory flow rate (IFR)

\begin{tabular}{lccc}
\hline DPI IFR $^{*}$ & Drug & Group & Lung deposition \% emitted dose \\
\hline Spiros $_{15}$ & Salbutamol sulphate & $\mathrm{n}=10$ normal & 37.4 \\
Chiesi60 & Salbutamol & $\mathrm{n}=10$ normal & 15.1 \\
Easyhaler60 & Salbutamol & $\mathrm{n}=10$ normal & 28.9 \\
Diskus60 & Salbutamol & $\mathrm{n}=\mathrm{x}$ normal & $16.6(\mathrm{pk})$ \\
& Futicasone propionate & $\mathrm{n}=\mathrm{x}$ asthmatic & $11.9(\mathrm{pk})$ \\
Turbuhaler60 & Salbutamol & $\mathrm{n}=8$ normal & 23.2 \\
& Budesonide & $\mathrm{n}=8$ asthmatic & 26.1 \\
Clickhaler57 & Beclomethasone dipropionate & $\mathrm{n}=8$ normal & 29.8 \\
Ultrahaler75 & Nedocrimal sodium & $\mathrm{n}=12$ normal & 13.3
\end{tabular}

Chiesi Chiesi Group, Parma, Italy; Clickhaler, Medeva Europe Ltd, Speke, United Kingdom; Diskus Glaxo Wellcome, Mississauga, Ontario; Easyhaler, Orion Pharma, Finland; Spiros, Dura Pharmaceuticals, San Diego, California; Turbuhaler, Astra Pharma Inc, Mississauga, Ontario; Ultrahaler, Rhône-Poulenc Rorer, United Kingdom. $n=x$ Not specificed; pk Pharmakokinetic

sol delivery systems. Major developments have occurred in DPI design as well as new concepts for the delivery of wet aerosols.

The criteria for removal of an existing CFC pMDI are also governed by the availability of these alternative delivery systems. These systems must provide the active drug substance via the same route ie, the inhaled route. Furthermore, the drug in the alternative device must be approved for the same clinical indication as the CFC pMDI, be as safe and have the same side effect profile as the CFC formulation, and provide approximately the same level of convenience for the patient. Apart from producing an innovative, cost effective design for each of these types of products, the need to demonstrate appropriate aerosol characteristics for inhalation into the lower respiratory tract, reproducibility in delivered dose of the active ingredient, and efficacy and safety comparable with the existing (CFC pMDI) product guarantees a time line of approximately five to 10 years from concept to market. Despite this huge investment of time and money by the pharmaceutical industry and the device manufacturers, dry powder inhalers and nebulizers should be viable alternatives to the CFC pMDI for a large segment of the patient population. It is anticipated that many of these new systems will be available well before the year 2005. However, young children and infants, patients in the intensive care unit and the elderly still need HFA pMDIs with holding chambers for effective therapy.

Dry powder inhalers: In the past few years, two new DPI designs have been approved for use in Canada with salmeterol xinafoate, fluticasone propionate and formoterol. A recent survey of patent applications and the literature suggests that there are approximately 10 to 20 devices in various stages of development in North America and Europe. Table 6 shows the range of lung deposition values for some of these inhalers. The studies were performed mostly in normal subjects and at the manufacturer's suggested inspiratory flowrate for optimal performance. Deposition values vary three- 
fold between these DPIs, but are still approximately half the value published for QVAR (17). Oropharyngeal doses (not shown) are about $60 \%$ for all the DPIs shown.

Of these systems, all but the Spiros (Dura Pharmaceuticals, San Diego, California) (not yet available in North America) and the Diskus (Glaxo Wellcome, Mississauga, Ontario) store the drug powder in a bulk reservoir. These two DPIs are examples of innovative multiunit dose systems that provide 60 to 80 individual doses of drug in either a rotating cassette (Spiros) or a coiled tape (Diskus). As with the pMDIs, all the devices listed give the patient the convenience of a one month's supply of drug in one inhaler.

\section{CONCLUSIONS}

The transition to HFA pMDI formulations of existing CFC pMDIs is proceeding in developed countries. There may be recognizable differences with some CFC-free pMDIs and potential advantages in delivery to the lung with others, the latter resulting from the reformulation process and improved canister hardware. Patients, physicians and healthcare professionals need to be made aware of the greater health issues necessitating the change, and that while the environmental benefits of reducing the CFC burden will not be evident for some years, the effects will be much more severe if not begun now. It should be stressed that the replacement pMDIs are as efficacious as the CFC ones and that the costs to the patient are currently the same as for the CFC pMDIs. Assurances must also be given to patients and physicians that, while transition is happening now, the removal of an existing CFC pMDI from the market will not occur until there are sufficient data and experience with the HFA replacement.

\section{REFERENCES}

1. Environment Canada. Canadian Initial Transition Strategy for the Phase-out of Chlorofluorocarbon (CFC) Use in Metered Dose Inhalers (MDIs). 1998. Internet Communication. www.ec.gc.ca/ozone/trans

2. IMS Canada. Compuscript. September 1997.

3. Molina MJ, Rowland FS. Stratospheric sink for chlorofluoromethanes: chlorine atom catalysed destruction of ozone. Nature 1974;249:810-2.

4. Hayman GD. CFCS and the ozone layer. Br J Clin Pract Suppl 1997;89:2-9.

5. June D, Carlson S, Ross D.The effect of temperature on drug delivery characteristics of chlorofluorocarbon (CFC) and hydrofluoroalkane (HFA) metered dose inhalers (MDIs). In: Dalby RN, Byron PR, Farr SJ, eds. Respiratory Drug Delivery V. Buffalo Grove: Interpharm Press, 1996:354-6.

6. Dolovich M, Leach CL. Drug delivery devices and propellants. In: Busse W, Holgate S, eds. Asthma and Rhinitis. Oxford: Blackwell Science, 1999. (In press)

7. Barry PW, O'Callaghan C. New formulation metered dose inhaler increases breath alcohol levels. Respir Med 1999;93:167-8.

8. Kleerup EC, Tashkin DP, Cline AC, Ekholm BP. Cumulative dose-response study of non-CFC propellant HFA 134a salbutamol sulfate metered-dose inhaler in patients with asthma. Chest 1996;109:702-7.

9. Bleecker ER, Tinkelman DG, Ramsdell J, et al. Proventil HFA provides bronchodilation comparable to Ventolin over 12 weeks of regular use in asthmatics. Chest 1998;113:283-9.

10. Tinkelman DG, Bleecker ER, Ramsdell J, et al. Proventil HFA and Ventolin have similar safety profiles during regular use. Chest 1998;113:290-6.

11. Dockhorn RJ, Wagner DE, Burgess GL, et al. Proventil HFA provides protection from exercise-induced bronchoconstriction comparable to Proventil and Ventolin. Ann Allergy Asthma Immunol 1997;79:85-8

12. Leach CL. Enhanced drug delivery through reformulating MDIs with HFA propellants-drug deposition and its clinical effect on preclinical programs. In: Dalby RN, Byron PR, Farr SJ, eds. Respiratory Drug Delivery V. Buffalo Grove: Interpharm Press, 1996:133-44.

13. Dubus JC, Rhem R, Dolovich M. In vitro characterization of salbutamol generic MDIs: delivery via small spacers. Eur Resp J 1998;12:65S. (Abst)

14. Donnell D, Harrison LI, Ward S, et al. Acute safety of the CFC-free propellant HFA-134a from a pressurized metered dose inhaler. Eur J Clin Pharmacol 1995;48:473-7.

15. Lipworth BJ, Clark DJ. Early lung absorption profile of non-CFC salbutamol via small and large volume plastic spacer devices. Br J Clin Pharmacol 1998;46:45-8.

16. Lipworth BJ, Clark DJ. Lung delivery of salbutamol by dry powder inhaler (Turbuhaler) and small volume antistatic metal spacer (Airomir CFC-free MDI plus NebuChamber). Eur Respir J 1997;10:1820-3.

17. Leach CL, Davidson PJ, Boudreau RJ. Improved airway targeting with the CFC-free HFA-beclomethasone metered-dose inhaler compared with CFC-beclomethasone. Eur Respir J 1998; 12:1346-53.

18. Richards JC, Pitcairn G, Sista S, Mahashabde S, Abramowitz W, Newman SP. A scintigraphic study to assess the deposition of flunisolide delivered by HFA and CFC metered dose inhalers. In: Dalby RN, Byron PR, Farr SJ, eds. Respiratory Drug Delivery VI. Buffalo Grove: Interpharm Press, 1998:405-6.

19. Johnson M. Fluticasone propionate:pharmacokinetic and pharmacodynamic implications of different aerosol delivery systems. In: Dalby RN, Byron PR, Farr SJ, eds. Respiratory Drug Delivery VI. Buffalo Grove: Interpharm Press, 1998:61-70.

20. Busse W, Colice GL, Donnell D, Hannon S. A dose-response dose-comparison of HFA-BDP and CFC-BDP based on FEV 1 and FEF25-75\%. Eur Respir J 1998;12:P0468. (Abst) 


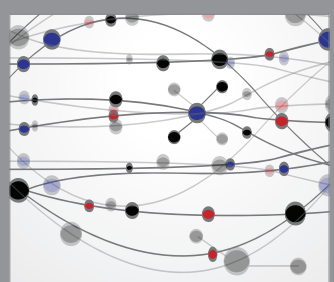

The Scientific World Journal
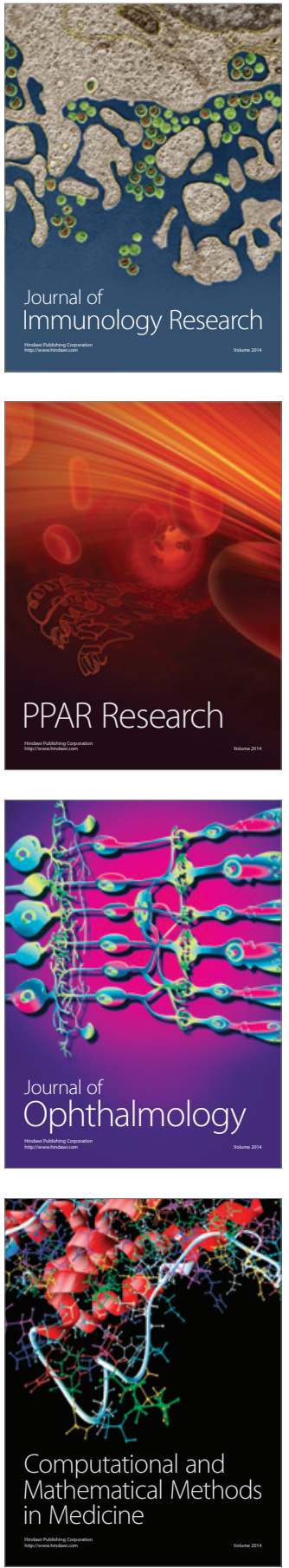

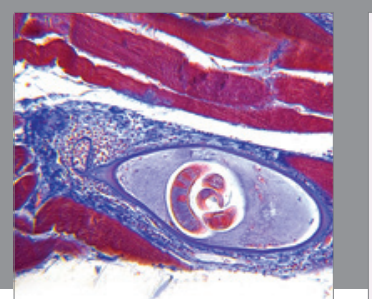

Gastroenterology Research and Practice

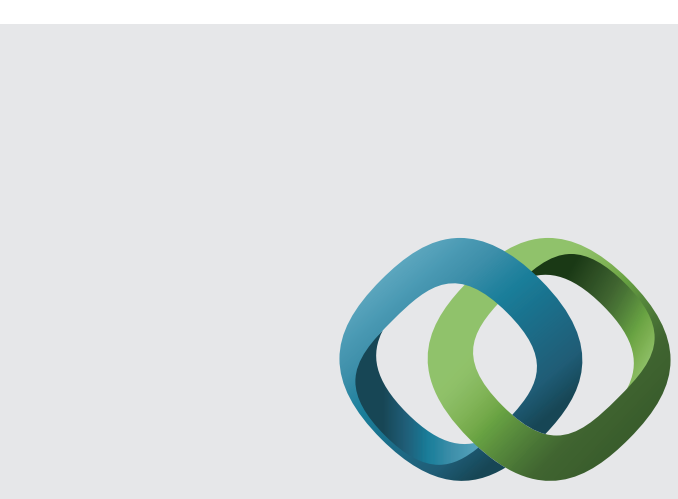

\section{Hindawi}

Submit your manuscripts at

http://www.hindawi.com
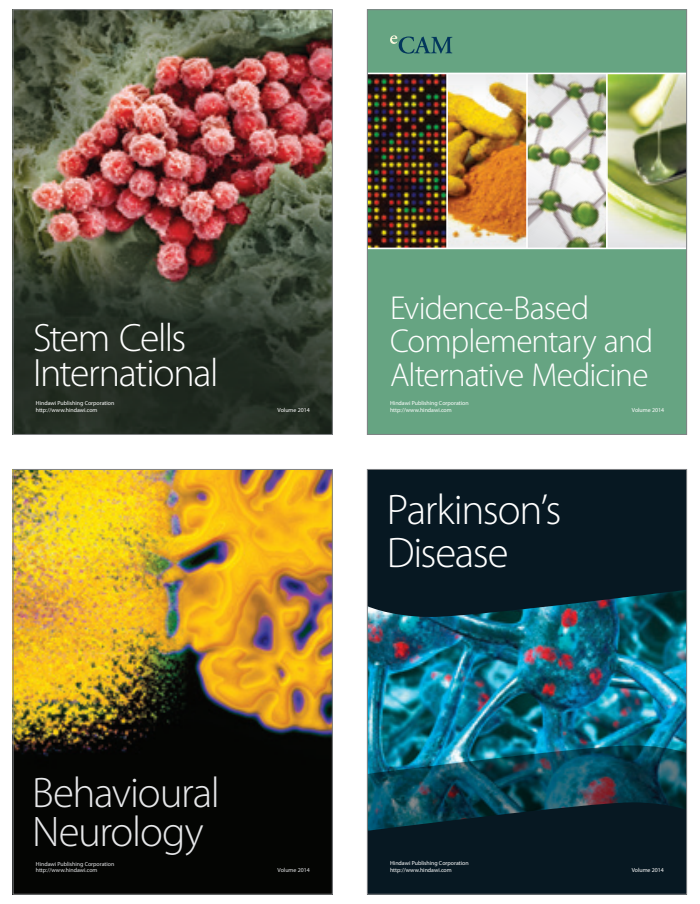
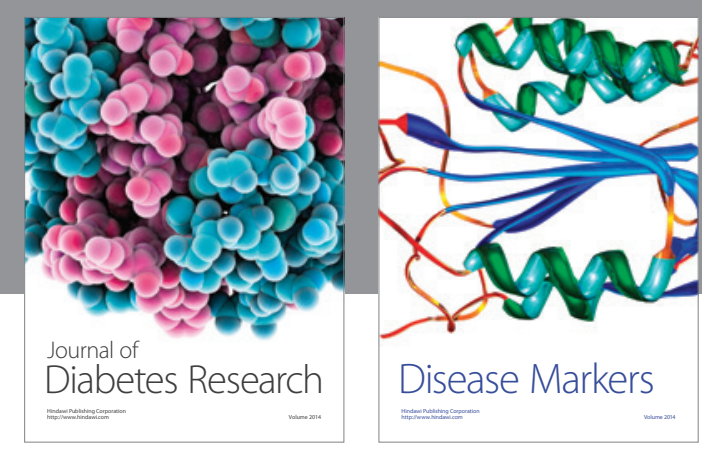

Disease Markers
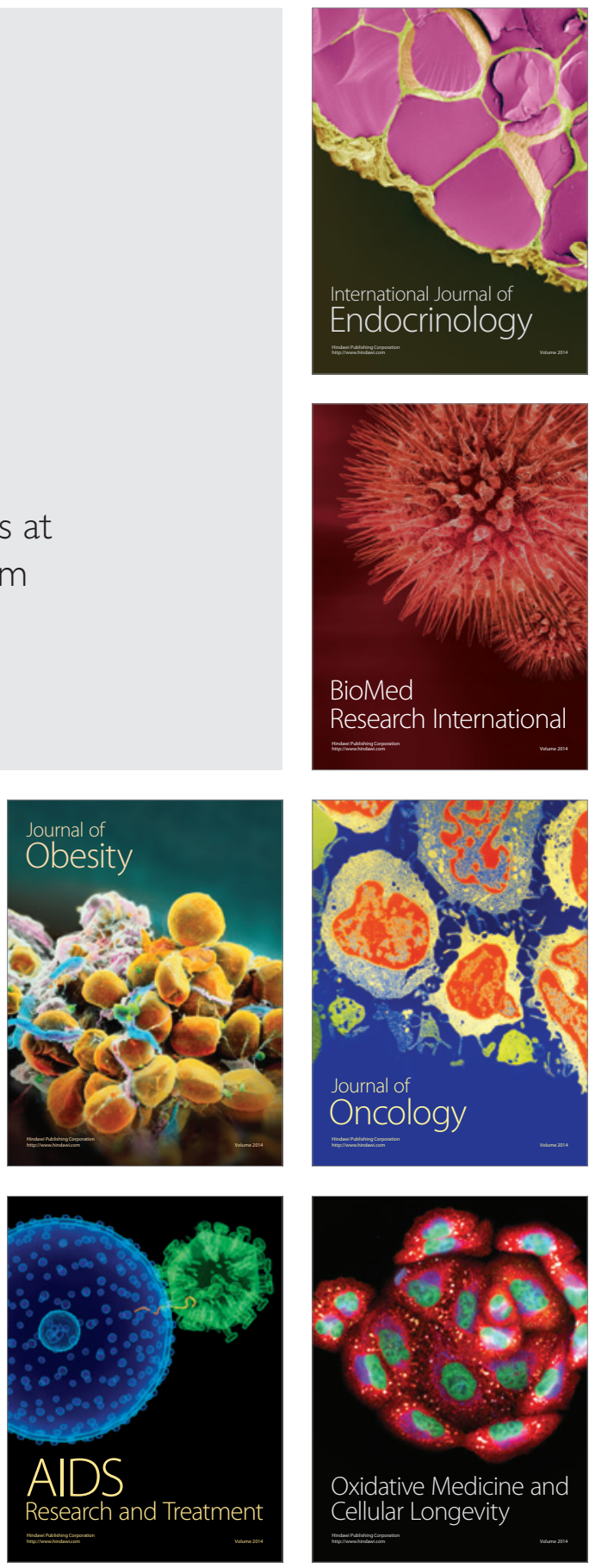